Cabranes, Flora. Exportaciones chinas y mexicanas hacia Estados Unidos: ¿sigue China afectando a México?

\title{
EXPORTACIONES CHINAS Y MEXICANAS HACIA ESTADOS UNIDOS: ¿SIGUE CHINA AFECTANDO A MÉXICO?
}

\section{CHINESE AND MEXICAN EXPORTS TO UNITED STATES: IS CHINA STILL AFFECTING MEXICO?}

\author{
FLORA CABRANES MÉNDEZ \\ Universidad Complutense de Madrid \\ Becaria MAEC-AECID \\ fcabrane@estumail.ucm.es \\ Fecha recepción: 7 de diciembre de 2010 \\ Fecha aceptación: 18 de mayo de 2011 \\ doi: 10.5209/rev_PADE.2011.v22.8
}

\section{RESUMEN}

El éxito de China como potencia exportadora y su creciente importancia en el mercado estadounidense ha afectado negativamente el comercio exterior de países como México, con exportaciones fuertemente concentradas hacia Estados Unidos y con una estructura exportadora similar a la de China. Sin embargo, en el periodo 2004-2009 se han observado ciertos signos de recuperación en las exportaciones mexicanas dirigidas a dicho mercado. Este trabajo aborda esta cuestión, comparando la evolución de las exportaciones chinas y mexicanas hacia Estados Unidos, para luego analizar si la recuperación de México se debe a cambios en el grado de competencia entre los productos de ambos países o a otros factores.

PALABRAS CLAVES: China, México, mercado estadounidense, exportaciones, competitividad, competencia comercial.

\section{JEL: F14}

\begin{abstract}
The success of China as a leading exporter and its growing importance in the U.S. market has negatively affected trade of countries such as Mexico, with highly concentrated exports to the United States and with an export structure similar to the one of China. However, in 2004-2009 there have been some signs of recovery in the Mexican exports to that market. This paper addresses this issue by comparing the evolution of Chinese and Mexican exports to U.S., for then examine whether the Mexican recovery is due to changes in the competition degree between the products of both countries or to other factors.
\end{abstract}

KEY WORDS: China, Mexico, U.S. market, exports, competitiveness, trade competition. 
Cabranes, Flora. Exportaciones chinas y mexicanas hacia Estados Unidos: ¿sigue China afectando a México?

\section{INTRODUCCIÓN}

En las últimas décadas, la economía china ha experimentado un gran dinamismo, que ha tenido como importante motor al sector exportador. Una muestra de su éxito en este rubro es la mejoría en su posición como potencia exportadora, pasando del puesto número 14 en cuanto a participación en las exportaciones mundiales totales en 1990 , al número uno en $2008^{1}$.

Sin embargo, este éxito ha causado importantes efectos adversos en el comercio exterior de algunos países, entre ellos México. Uno de estos efectos es el creciente déficit comercial con China, el cual pasó de 6,9 millones de dólares en 1990, a 30,3 miles de millones de dólares en 2009. Además, China es ya el segundo país origen de las importaciones mexicanas, representando en 2009 el 13,9\% del total de éstas ${ }^{2}$, siendo sólo superado por Estados Unidos.

Por otro lado, como señalan diversos estudios ${ }^{3}$, esto también ha afectado negativamente al comportamiento exportador de México a Estados Unidos, siendo esto último de gran importancia para el país latinoamericano, ya que sus ventas al exterior se encuentran fuertemente concentradas hacia el mercado estadounidense, al cual se destinó en 2009 el 80,5\% del total de las exportaciones mexicanas, habiendo años en que incluso este porcentaje llegó a más del $88 \% 4$.

De acuerdo a estos estudios, China y México tienen estructuras exportadoras similares, lo que hace que sus productos sean competidores entre sí y no complementarios. Así, la competencia china, especialmente a partir de la entrada de este país a la OMC en diciembre de 2001, explicaría al menos en parte el estancamiento de las exportaciones mexicanas hacia Estados Unidos en el periodo 2001-2003 y el progresivo descenso que la participación de las importaciones estadounidenses provenientes de México tuvieron con respecto al total de las importaciones de dicha potencia económica en el periodo 2003-2005.

\footnotetext{
${ }^{1}$ En base a cálculos obtenidos del Handbook of Statistics online, de la UNCTAD.

${ }^{2}$ En base a datos tomados de la SE (2010).

${ }^{3}$ Algunos de estos estudios son, por un lado: Blázquez-Lidoy, Rodríguez y Santiso (2006), Jenkins (2009), enfocados al impacto de China en América Latina, aunque concluyen que el país de esta región más afectado por la competencia comercial en terceros mercados ha sido México; y por otra parte: Chávez y Leyva (2007), Correa (2008), De la Cruz y González (2007), Iranzo y Ma (2006), Leyva (2009) y Romero (2009), que abordan la competencia comercial global entre México y China para el mercado de Estados Unidos.

También se han realizado otras investigaciones incluso más específicas, como la de Correa y Gómez (2010), enfocada a los bienes de tecnología avanzada. Todos estos estudios, realizados para distintos periodos de tiempo, confirman la existencia de un desplazamiento de exportaciones mexicanas por productos chinos en dicho mercado en la última década y, como señala la evidencia empírica analizada en ellos, éste se ha dado especialmente a partir de su entrada como miembro a la OMC.

Asimismo, ciertos estudios analizan otro tipo de impactos de China en diversos países de América Latina. Por ejemplo el de Jenkins (2009), que apunta a que en el rubro de inversión extranjera directa, México es el país de esta región más amenazado frente a China. (Esto podría tener también efectos adversos en las exportaciones mexicanas, ya que una parte importante de éstas procede de empresas de capital extranjero). De acuerdo al mismo estudio, el enorme tamaño de la economía china afecta también a los precios mundiales, reduciéndolos en el caso de los bienes manufacturados, que exporta en grandes cantidades. Esto tendría un efecto negativo para México, quien también exporta este tipo de productos.

${ }^{4}$ Según datos obtenidos de la SE (2010).
} 
Cabranes, Flora. Exportaciones chinas y mexicanas hacia Estados Unidos: ¿sigue China afectando a México?

No obstante, las estadísticas oficiales y algunos trabajos como el de Leyva (2009) señalan una leve recuperación para México en los últimos años. Dada la relevancia para la economía mexicana del desplazamiento de sus exportaciones por productos chinos y tomando en cuenta que al parecer no existen investigaciones recientes que profundicen en la aparente recuperación observada, el presente trabajo busca descubrir si China sigue afectando a México en este aspecto, para lo cual se plantea responder a las siguientes preguntas específicas:

- ¿En qué ha variado el comportamiento de las exportaciones mexicanas y chinas hacia Estados Unidos en el periodo 2004-2009, con respecto al de 1990-2003?

- ¿En qué medida los productos chinos y los mexicanos siguen o no compitiendo entre sí en el mercado estadounidense?

- ¿Cuáles son las posibles causas de los cambios de comportamiento observados en los últimos años?

Dichas cuestiones se consideran importantes debido a que un mayor conocimiento de la realidad actual y sus determinantes, sería de gran utilidad para la toma de decisiones de México en cuanto a la búsqueda de estrategias para evitar o reducir los impactos negativos en su capacidad exportadora, ante el auge de China como potencia exportadora mundial.

Para responder las preguntas anteriores, primero se presentará un apartado que muestra la evolución de las importaciones estadounidenses provenientes de ambos países, tanto en valor como en términos de cuota del mercado de Estados Unidos, entre otros aspectos. En el segundo apartado, siguiendo la metodología utilizada por otros autores ${ }^{5}$, se comparará la estructura exportadora de ambos países, a fin de confirmar si los productos chinos y los mexicanos siguen compitiendo o no entre sí en el mercado estadounidense. En el tercer apartado, se sugerirán algunas posibles causas de los cambios observados en los apartados anteriores. Finalmente, se dará paso a las conclusiones.

\section{COMPORTAMIENTO DE LAS EXPORTACIONES MEXICANAS Y CHINAS HACIA ESTADOS UNIDOS EN EL PERIODO 1990-2009}

Para tratar este punto, se utilizarán en su mayoría datos de la United States International Trade Commission, referentes a importaciones estadounidenses provenientes tanto de China como México, a fin de que los datos puedan ser comparables al utilizar la misma fuente. Para todos los datos referentes a importaciones se empleará el valor CIF, el cual incluye el costo de la mercancía, del seguro y del flete.

Para analizar la evolución del comportamiento de las exportaciones mexicanas y chinas hacia Estados Unidos y detectar si en los últimos años la situación para México ha variado o no, se utilizarán los siguientes criterios: valor y tasas medias de crecimiento anual de las importaciones estadounidenses provenientes de ambos países; participación de éstas en el mercado de Estados Unidos; y concentración de las exportaciones mexicanas en dicho mercado.

\footnotetext{
${ }^{5}$ Principalmente las seguidas por Blázquez-Lidoy, Rodríguez y Santiso (2006) y Romero (2009) en cuanto a índices de competencia comercial y de especialización.
} 
Cabranes, Flora. Exportaciones chinas y mexicanas hacia Estados Unidos: ¿sigue China afectando a México?

El uso de estos indicadores es acorde a la perspectiva expuesta por Correa y Gómez (2010), según la cual una mejora en competitividad internacional (ya sea a nivel global o en un mercado en particular) consiste en un mayor crecimiento de exportaciones y una mejoría en la participación en el mercado internacional (o en este caso, en el estadounidense, que es el de interés para este estudio).

\section{- Valor y tasas medias de crecimiento anual de las importaciones estadounidenses provenientes de China y México ${ }^{6}$}

Entre 1990 y 2001, tanto las importaciones de Estados Unidos procedentes de China como de México habían tenido una tendencia similar aunque siendo mayores las de este último. Esta situación se modificó a partir de 2002, cuando las de China comenzaron a expandirse con creces, coincidiendo esto con la reciente incorporación del país asiático a la OMC, en diciembre de 2001. Su crecimiento acelerado ha continuado hasta 2007, presentándose una ligera desaceleración en 2008 y, por primera vez en el periodo, un descenso en 2009, como resultado del impacto de la crisis económica internacional actual. (Ver gráfico 1).

Por su parte, las de México pasaron de haber crecido ininterrumpidamente desde 1990 hasta 2000, a un descenso de $-3,3 \%$ en 2001 con respecto al año anterior, siendo hasta 2003 que se lograron alcanzar niveles superiores a los de 2000. Tras dicho periodo de estancamiento (que no fue exclusivo de las importaciones estadounidenses procedentes de México, sino también de las que provenían de Canadá y Japón, los dos principales proveedores de dicho mercado en la década de los noventa), siguieron creciendo ininterrumpidamente hasta 2008, aunque de forma menos acelerada que las de China. (Ver gráfico 1).

\section{Gráfico 1: Importaciones de Estados Unidos, por principales países de origen}

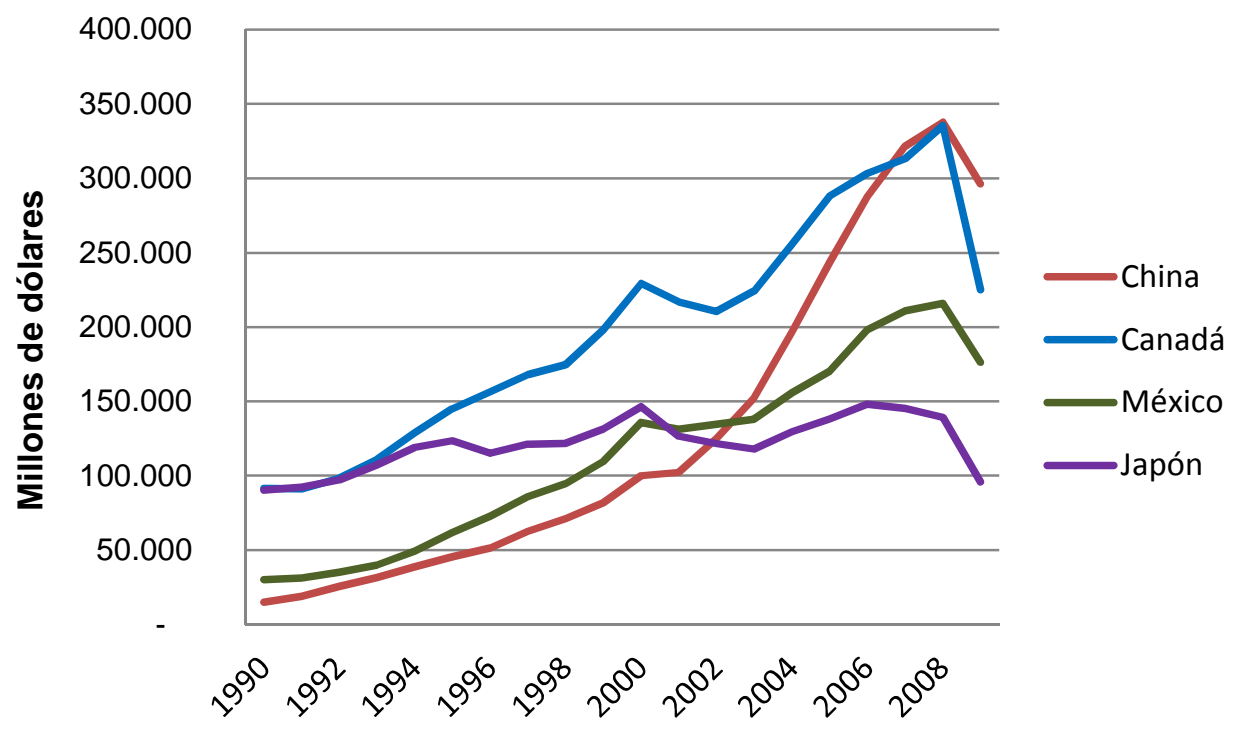

Fuente: Elaboración propia con datos de la United States International Trade Commission. Nota: Se introdujeron datos de Japón y Canadá que, junto con México y China, son los principales países de origen de las importaciones estadounidenses. Lo anterior, para poder visualizar con más claridad el papel de estos dos últimos en dicho mercado. Estos cuatro países en su conjunto han constituido en todos los años del periodo 1999-2009 alrededor del $50 \%$ de las importaciones totales de Estados Unidos.

\footnotetext{
${ }^{6}$ Los datos de este apartado tomaron como referencia las cifras de la United States International Trade Commission (2010).
} 
Cabranes, Flora. Exportaciones chinas y mexicanas hacia Estados Unidos: ¿sigue China afectando a México?

Así, en base al comportamiento observado en el periodo de referencia, se pueden distinguir tres etapas de interés:

a) 1994-2000: Las importaciones estadounidenses provenientes de México estuvieron creciendo con fuerza, especialmente a raíz de la entrada en vigor del Tratado de Libre Comercio de América del Norte (TLCAN) en 1994 y de la devaluación del peso mexicano en el mismo año. En dicho periodo, la tasa media de crecimiento anual (TMCA) de éstas fue de 18,2\%, mientras que para las procedentes de China fue de $17,3 \%$, siendo ambas cifras muy superiores a la TMCA de las importaciones totales estadounidenses, que fue de 10,6\%. (Ver gráfico 2).

b) 2001-2003: 2001 fue un año de crisis económica en Estados Unidos, lo que produjo una reducción en el total de sus importaciones ${ }^{7}$ con respecto al año anterior, siendo sólo hasta 2003 que logró rebasarse ligeramente el total importado en 2000. Como efecto de lo anterior, se observa en este periodo una desaceleración en el crecimiento total de importaciones estadounidenses con respecto al periodo 1994-2000, siendo su TMCA de 5,0\%.

De entre las importaciones estadounidenses, las de origen mexicano se vieron incluso más afectadas, siendo su TMCA de 2,5\%, mientras que las de origen chino se dispararon, alcanzando una TMCA de 22,1\%, coincidiendo con la entrada de China a la OMC en diciembre de 2001. (Ver gráfico 2).

En este periodo también se presentó un fuerte declive en la base industrial de capital estadounidense en el territorio mexicano, origen de una parte significativa de las ventas de México al exterior. El ingreso de China a la OMC y la desventaja del país latinoamericano en cuanto a costos de producción habrían contribuido fuertemente a ello. Como ejemplo de esto, baste señalar que en 2002 el salario mensual en el sector manufacturero chino fue de 112 dólares y de aproximadamente 440, es decir, casi cuatro veces más, en México. (Rosas, 2010 y Blázquez-Lidoy, Rodríguez y Santiso, 2006).

Asimismo, según datos tomados de INEGI (2011), en junio de 2001 existían en este país 3.735 establecimientos pertenecientes a la industria maquiladora de exportación (de capital principalmente extranjero y procedente en su mayoría de Estados Unidos), siendo éste el máximo histórico alcanzado, mientras que para septiembre de 2003 esta cantidad ya se había reducido a 2.775, lo que implica una pérdida cercana a mil establecimientos y correspondiente a prácticamente la cuarta parte del total.

c) 2004-2008: Este periodo fue de crecimiento en la economía de Estados Unidos, lo cual permitió que sus importaciones se reactivaran. Se observa una notable recuperación en las de origen mexicano (con una TMCA de 8,5\%, cifra muy superior al 2,5\% alcanzado en 2001-2003 y por encima también del 7,4\% que registraron las importaciones estadounidenses totales).

Por otro lado, el crecimiento de las importaciones procedentes de China superó al de las mexicanas, alcanzando una TMCA de 14,5\%, siendo éste un

\footnotetext{
${ }^{7}$ Palazuelos (2009). 
Cabranes, Flora. Exportaciones chinas y mexicanas hacia Estados Unidos: ¿sigue China afectando a México?

incremento muy relevante, especialmente si se toma en cuenta que se partían de niveles muy elevados, por lo que crecer a este ritmo era más difícil que si se partiera de niveles inferiores. Un posible factor que pudo haber influido en este comportamiento favorable para China fue la reducción por etapas hasta la eliminación final el 1 de enero de 2005 de los cupos sobre los artículos textiles y de confección en virtud del Acuerdo sobre los Textiles y el Vestido (ATV) de la OMC, mencionada por Jenkins (2009), lo cual habría permitido una mayor importación estadounidense de productos chinos de los sectores textil y confección, en los que el país asiático se ha caracterizado por producir a costes muy bajos en comparación a otros países.

Sin embargo, a pesar de que el comportamiento chino fue mejor que el mexicano, es notable una reducción en el diferencial de crecimiento de las importaciones provenientes de ambos países, con una importante recuperación para México, si bien su ritmo de crecimiento fue en este periodo menos acelerado que en 1994-2000. (Ver gráfico 2).

\section{Gráfico 2: Tasa media de crecimiento anual de las importaciones de Estados Unidos totales y procedentes de China y México}

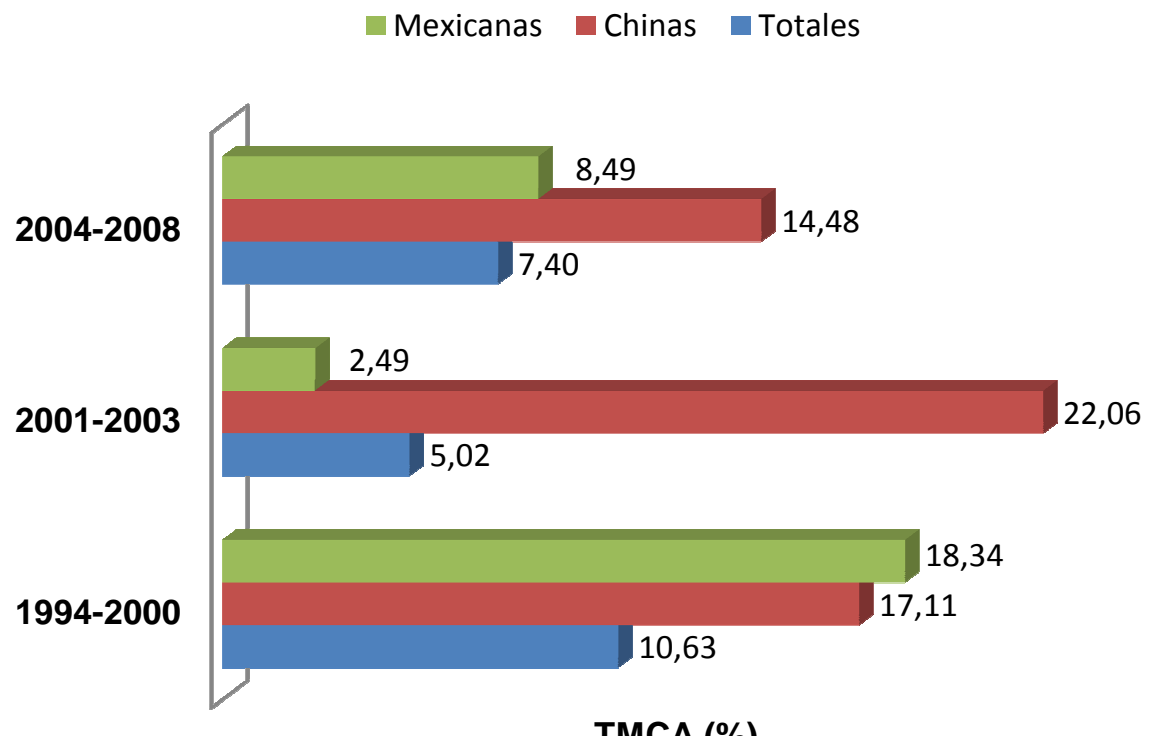

TMCA (\%)

Fuente: Elaboración propia a partir de datos de la United States International Trade Commission.

Cabe mencionar que 2009 fue un año atípico, con una disminución de 25,8\% en las importaciones totales de Estados Unidos con respecto a 2008, como consecuencia de la severa crisis financiera internacional que se gestó en este país y cuyos efectos se dispararon con gran fuerza en el segundo semestre de 2008 y en $2009^{8}$. Las importaciones provenientes de China y México también experimentaron decrementos (de 12,3\% y 18,2\% respectivamente), lo cual sigue mostrando un comportamiento más favorecedor para el primer país, aunque el del segundo no fue tan negativo si se le compara con el de las importaciones totales o por ejemplo, con las de origen canadiense, que retrocedieron en un $33 \%{ }^{9}$.

\footnotetext{
${ }^{8}$ Krugman (2009) y United States International Trade Commission (2010).

${ }^{9}$ Cifras calculadas en base a datos de la United States International Trade Commission (2010).
} 
Cabranes, Flora. Exportaciones chinas y mexicanas hacia Estados Unidos: ¿sigue China afectando a México?

- Participación de China y México en el mercado estadounidense

Desde 1990 hasta 2002, la participación de los productos mexicanos en el mercado estadounidense fue superior a la de los productos chinos y creciente, pasando de representar un 5,95\% en 1990, a un $11,32 \%$ en 2002. En 2003, China superó a México por primera vez en este rubro, desplazándolo como segundo país más importante en cuanto a origen de las importaciones a dicho mercado. Asimismo, la participación de los productos de origen mexicano en el mercado estadounidense se fue reduciendo año tras año durante el periodo 2003-2005, mientras que la de los productos chinos continuaba en ascenso. (Ver gráfico 3 y tabla 1).

No obstante, la ganancia de China fue superior a la pérdida de México, lo que indica que también ha desplazado exportaciones de otros países, como es el caso de Japón y Canadá. (Leyva, 2009). De hecho, en 2007, China logró desplazar a este último, convirtiéndose en el principal proveedor de las importaciones de Estados Unidos.

Para el periodo 2006-2009, México tuvo una ligera recuperación en esta área, con excepción de 2008, año en que también la participación de los productos chinos en dicho mercado retrocedió. Así, aunque desde 2003 China ha estado superando a México ininterrumpidamente, es importante resaltar la ligera recuperación que se ha estado dando en México en los últimos años, misma que es incluso más llamativa si se compara con la de los productos procedentes de Canadá (principal origen de las importaciones estadounidenses hasta 2006), cuya participación se ha reducido año tras año desde 2003 hasta 2009. Es también notable la pérdida de participación de Japón en dicho mercado, quien pasó de ser el principal proveedor estadounidense en 1990, a ocupar el cuarto puesto desde 2002. (Ver gráfico 3 y tabla 1).

\section{Gráfico 3: Participación de China, Canadá y México en las importaciones de Estados Unidos}

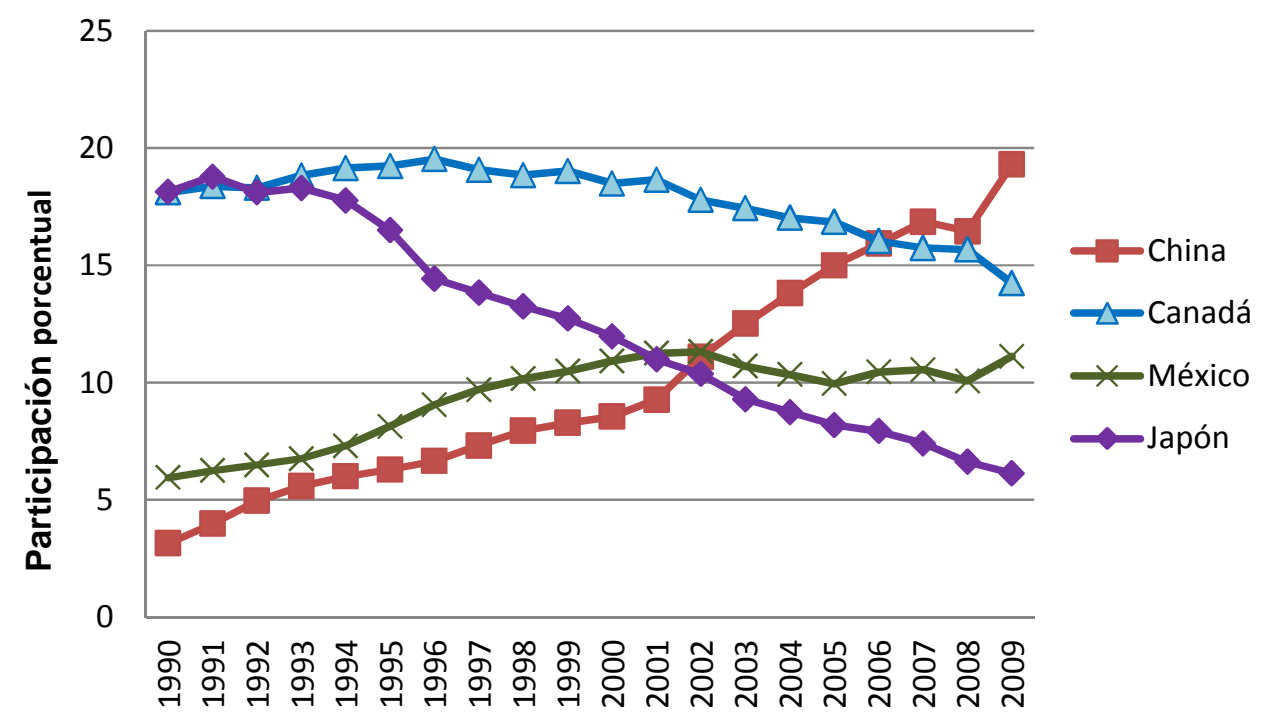

Fuente: Elaboración propia con datos de la United States International Trade Commission 
Cabranes, Flora. Exportaciones chinas y mexicanas hacia Estados Unidos: ¿sigue China afectando a México?

Tabla 1: Participación de China, Canadá, Japón y México en las importaciones estadounidenses

\begin{tabular}{|ccccc|}
\hline Año & China & Canadá & México & Japón \\
\hline $\mathbf{1 9 9 0}$ & 3,15 & 18,11 & 5,95 & 18,13 \\
\hline $\mathbf{1 9 9 1}$ & 3,98 & 18,37 & 6,25 & 18,78 \\
\hline $\mathbf{1 9 9 2}$ & 4,95 & 18,30 & 6,48 & 18,12 \\
\hline $\mathbf{1 9 9 3}$ & 5,58 & 18,83 & 6,75 & 18,30 \\
\hline $\mathbf{1 9 9 4}$ & 6,00 & 19,15 & 7,31 & 17,77 \\
\hline $\mathbf{1 9 9 5}$ & 6,29 & 19,24 & 8,14 & 16,50 \\
\hline $\mathbf{1 9 9 6}$ & 6,65 & 19,53 & 9,06 & 14,42 \\
\hline $\mathbf{1 9 9 7}$ & 7,33 & 19,08 & 9,70 & 13,83 \\
\hline $\mathbf{1 9 9 8}$ & 7,95 & 18,85 & 10,17 & 13,24 \\
\hline $\mathbf{1 9 9 9}$ & 8,29 & 19,03 & 10,48 & 12,73 \\
\hline $\mathbf{2 0 0 0}$ & 8,55 & 18,50 & 10,92 & 11,97 \\
\hline $\mathbf{2 0 0 1}$ & 9,27 & 18,65 & 11,25 & 10,99 \\
\hline $\mathbf{2 0 0 2}$ & 11,10 & 17,79 & 11,32 & 10,37 \\
\hline $\mathbf{2 0 0 3}$ & 12,51 & 17,44 & 10,70 & 9,29 \\
\hline $\mathbf{2 0 0 4}$ & 13,80 & 17,03 & 10,35 & 8,74 \\
\hline $\mathbf{2 0 0 5}$ & 15,00 & 16,85 & 9,96 & 8,19 \\
\hline $\mathbf{2 0 0 6}$ & 15,93 & 16,04 & 10,45 & 7,93 \\
\hline $\mathbf{2 0 0 7}$ & 16,86 & 15,74 & 10,55 & 7,41 \\
\hline $\mathbf{2 0 0 8}$ & 16,45 & 15,68 & 10,07 & 6,62 \\
\hline $\mathbf{2 0 0 9}$ & 19,30 & 14,24 & 11,12 & 6,14 \\
\hline & $\mathbf{2 0}$ \\
\hline
\end{tabular}

Fuente: Elaboración propia con datos de la United States International Trade Comisión.

Sin embargo, si se compara la participación de China y México en las importaciones estadounidenses para todo el periodo 1990-2009, el incremento de más de cinco puntos porcentuales presentado en México palidece frente al de más de 16 puntos porcentuales observado en China.

Por otro lado, cabe resaltar que, como señala Rosas (2010), en febrero de 2010 México incrementó su participación como proveedor del mercado estadounidense hasta llegar a 12,2\%. Además, el valor de las exportaciones mexicanas a Estados Unidos en dicho periodo registró un alza anual de $32,6 \%$, su incremento más alto en 16 años.

Por último, cabe mencionar los resultados encontrados por otros autores, tales como Jenkins (2009), que realizó un estudio en el que calculó la pérdida de cuota de mercado de los países latinoamericanos con respecto a China. De acuerdo a su análisis, entre 2001 y 2006 México tuvo una pérdida de $11,4 \%$ en sus exportaciones a Estados Unidos con respecto al país asiático (medido como porcentaje del total de sus exportaciones a dicho mercado), siendo el tercer país de América Latina más afectado por China, después de República Dominicana y El Salvador. Por otro lado, 
Cabranes, Flora. Exportaciones chinas y mexicanas hacia Estados Unidos: ¿sigue China afectando a México?

entre 2004 y 2006 ésta fue de 4,5\%, lo que refleja un comportamiento también negativo aunque mucho menor. En este periodo, posterior a la supresión de las cuotas fijadas por el ATC, se vieron más afectadas las exportaciones de otros países que dependían fuertemente de productos textiles y de prendas de vestir.

Por su parte, el trabajo de Leyva (2009) señala que si bien México ha experimentado una recuperación en los últimos años en cuanto a su cuota de participación en el mercado estadounidense, no ha logrado alcanzar de nuevo los niveles de 2001; y su recuperación ha sido inferior al incremento de la de China. De hecho, Guerrero y Padilla (2010), comparando 2002 con 2008, observaron que el 22,9\% de los productos mexicanos ganaron participación de mercado en Estados Unidos, contra un $98,4 \%$ para el caso de China.

\section{- Concentración de las exportaciones mexicanas en el mercado estadounidense.}

Entre 1995 y 2000 se registró una concentración cada vez mayor de las exportaciones mexicanas en el mercado de Estados Unidos, alcanzando éstas en el último año el 88\% de las exportaciones totales de México. Si bien en 2001 este indicador había disminuido a 85,9\%, en 2002 y 2003 se alcanzó de nuevo una proporción de alrededor del $88 \%$.

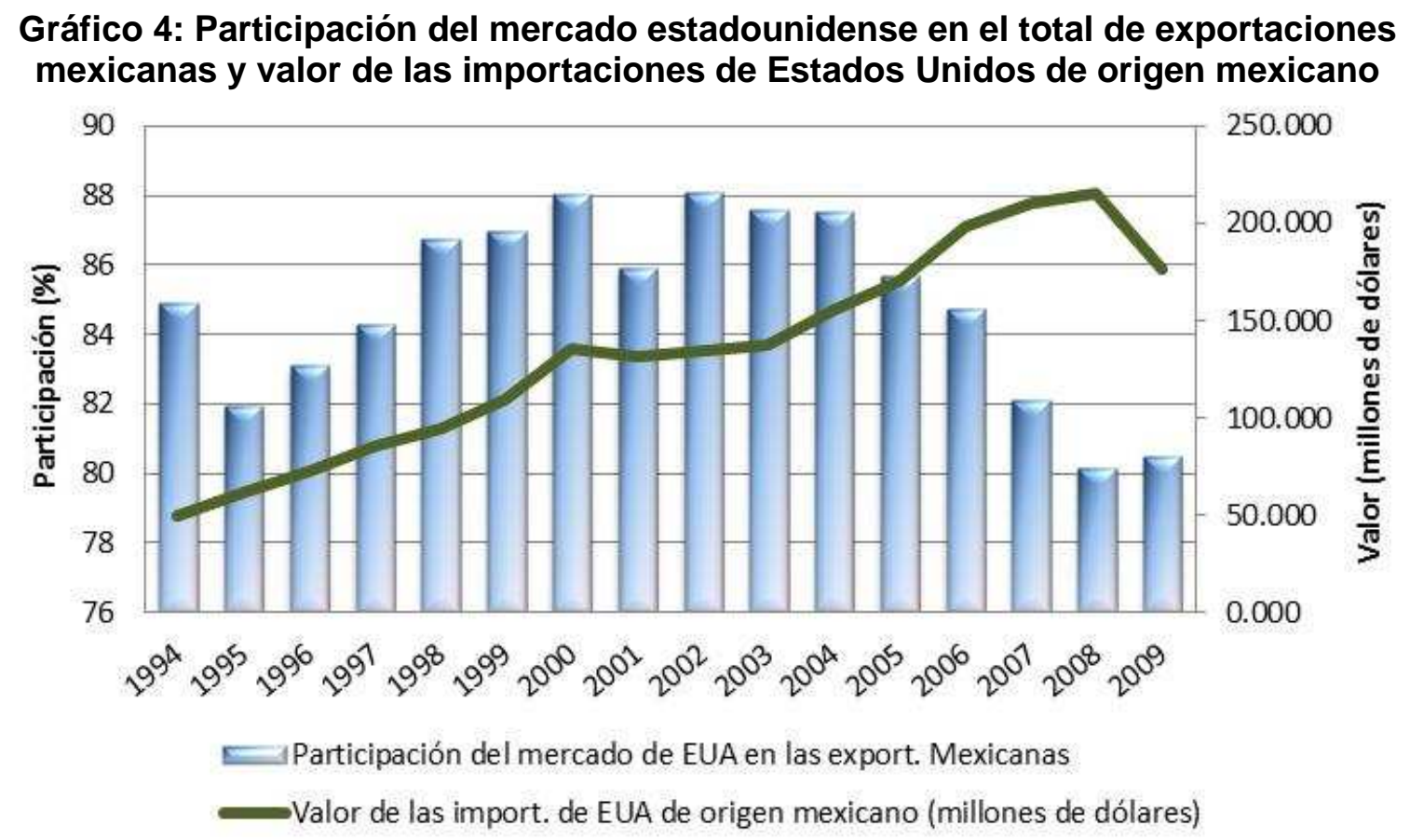

Fuente: Elaboración propia con datos de la Secretaría de Economía (de México) y de la United States International Trade Comisión

Posteriormente, en el periodo 2004-2008, la concentración de las exportaciones mexicanas en dicho mercado fue decreciendo paulatinamente, pasando de un $87,5 \%$ en 2004 , a $80,2 \%$ en 2008 . (Ver gráfico 4). Esto es relevante, en la medida en que torna incluso más llamativa la recuperación de las exportaciones del país latinoamericano hacia Estados Unidos señalada en los apartados anteriores (tanto en valor como en TMCA y en cuota del mercado estadounidense), pues implica que ésta no se debió simplemente a que México aumentara la proporción de sus ventas 
Cabranes, Flora. Exportaciones chinas y mexicanas hacia Estados Unidos: ¿sigue China afectando a México?

al exterior hacia dicho destino, sino que las exportaciones totales mexicanas aumentaron en forma tal que permitieron esta recuperación, aun cuando la concentración en el mercado estadounidense se redujo en el periodo 2004-2008.

De este apartado se puede concluir entonces que en los últimos años las exportaciones mexicanas hacia Estados Unidos experimentaron un mejor desempeño con respecto al periodo 2001-2003, no obstante que su comportamiento es en algunos aspectos más pobre que en 1994-2000 y además, muy inferior al de China. Como se ha expuesto, la recuperación se observa en los siguientes puntos:

- El crecimiento ininterrumpido en el valor de las mismas, desde 2003 hasta 2008.

- Cierta recuperación de la TMCA en 2004-2008, la cual fue superior a la de 20012003 y a la del total de importaciones estadounidenses.

- Retroceso en 2009 asociado a la contracción de la demanda de Estados Unidos ocasionada por la crisis financiera internacional, aunque menor al de las importaciones totales de este país y al de las provenientes de Canadá.

- Recuperación desde 2006 en la participación del mercado estadounidense.

- Los elementos anteriores se dieron a pesar de que la parte de las exportaciones dirigidas hacia Estados Unidos dentro del total de las exportaciones mexicanas se redujo.

Cabe entonces preguntarse el por qué de ésta y si se ha debido a causas estructurales (tales como si las estructuras exportadoras de China y México compiten ahora menos que en el pasado; o si en los últimos años este último país ha logrado competir mejor que antes); a causas coyunturales, tales como el incremento en los precios del petróleo o aumento en la competitividad mexicana debido a fluctuaciones en el tipo de cambio, entre otros; o a una combinación de ambas.

\section{2. ¿SIGUEN COMPITIENDO ENTRE SÍ LAS EXPORTACIONES MEXICANAS Y LAS CHINAS, EN EL MERCADO DE ESTADOS UNIDOS?}

Para dar respuesta a esta pregunta, se siguieron dos metodologías, basadas en la construcción y análisis de indicadores de especialización comercial. Existen diversos indicadores de este tipo ${ }^{10}$; sin embargo, para este trabajo se eligió el uso de los siguientes:

\section{1 Índices de similitud o de competencia comercial}

Como señala Romero (2009), para medir la competencia comercial entre dos economías en el mundo o en un mercado en particular, se suelen utilizar los índices de similitud, también llamados de competencia comercial por autores como Blázquez-Lidoy, Rodríguez y Santiso (2006), los cuales muestran si la estructura de las exportaciones de dos países se asemeja, en cuyo caso la probabilidad de que compitan de manera directa en el mercado tomado como referencia es mayor.

\footnotetext{
${ }^{10}$ En Durán y Álvarez (2008) puede consultarse todo un catálogo de indicadores de comercio exterior que se utilizan para la medición de posición y dinamismo comercial. Dichos autores presentan las principales características de cada indicador, junto con su forma de construirlos. Asimismo, en trabajos como los de Correa (2008), Correa y Gómez (2010), Guerrero y Padilla (2010), Jenkins (2009), Leyva (2009) y Romero (2009), se utilizan diversos indicadores y metodologías para analizar casos concretos.
} 
Cabranes, Flora. Exportaciones chinas y mexicanas hacia Estados Unidos: ¿sigue China afectando a México?

Para este trabajo se eligieron dos índices de similitud, utilizados en un estudio que se cita con frecuencia: el de Blázquez-Lidoy, Rodríguez y Santiso (2006), en el cual se comparaba la estructura exportadora de China con la de 34 países. Sin embargo, existen otros, como el Índice Ponderado de Similitud de las Exportaciones (IPSE) y el Finger-Kreinin de Similitud de las Exportaciones (FK), que ofrecen distintas formas de medir el mismo fenómeno. (Leyva, 2009 y Romero, 2009).

Los índices de competencia utilizados fueron el coeficiente de conformidad (CC) y el coeficiente de especialización (CS) y:

$$
C C=\frac{\sum_{n} a_{i t}^{n} a_{j i}^{n}}{\sqrt{\sum_{n}\left(a_{i t}^{n}\right)^{2} \sum_{n}\left(a_{j i}^{n}\right)^{2}}} \quad C S=1-\frac{1}{2} \sum_{n}\left|a_{i t}^{n}-a_{j}^{n}\right|
$$

donde $a_{i t} y a_{j t}$ representan la participación del producto $n$ en el total de exportaciones del país $i$ o del país $j$ en el periodo $t$.

Debido a que este trabajo se enfoca exclusivamente en la competencia entre México y China con respecto al mercado estadounidense, en el cálculo de ambos índices uno de estos dos países fue considerado como $i$ y el otro como $j$, mientras que en lugar de circunscribirse al total de sus exportaciones, se tomaron como referencia sólo las que se dirigían a Estados Unidos.

A fin de que los datos fueran comparables, se utilizaron las cifras de importaciones estadounidenses provenientes de México y de China, publicadas por la United States International Trade Commission (2010). La desagregación a nivel producto que se tomó fue la Standard International Trade Classification (SITC), a un nivel de tres dígitos (implicando esto un total de 266 productos diferentes para cada país). Se tomaron los datos correspondientes al valor CIF de importación ${ }^{11}$.

Por su naturaleza, los índices pueden arrojar valores entre 0 y 1 , significando 1 estructuras exportadoras idénticas y por ende, potencial competencia comercial muy elevada; mientras que un valor de 0 indica que no hay coincidencia entre las estructuras.

Ambos índices se calcularon para cada año del periodo $1996-2009^{12}$ y, al igual que en Blázquez-Lidoy, Rodríguez y Santiso (2006), se calculó también el promedio aritmético de ambos índices, al que se le denominó $\mathrm{Cl}$.

De acuerdo al estudio de los autores señalados, de los 34 países que se tomaron en cuenta, México fue el que tuvo el cuarto $\mathrm{Cl}$ más elevado $(0,55)$ para el promedio del periodo 2002-2004, lo que implica que fue uno de los países que mostró tener una mayor competencia comercial con China, siendo sólo superado por la República de Corea, Hungría y Tailandia; y ubicándose muy por encima de los demás países de

\footnotetext{
${ }^{11}$ Como ya se indicó en otro apartado, el valor CIF incluye el coste de la mercancía, del seguro y del flete.

${ }^{12}$ No se tomaron datos previos debido a que el sistema de clasificación de productos era diferente, lo que hacía que los datos no fueran comparables.
} 
Cabranes, Flora. Exportaciones chinas y mexicanas hacia Estados Unidos: ¿sigue China afectando a México?

América Latina. Según el mismo estudio, México fue además uno de los pocos países latinoamericanos (cuatro de quince) que experimentaron un incremento en su $\mathrm{Cl}$ en 2001-2004, con respecto a $1998-2001^{13}$, lo que indica un aumento en su competencia comercial potencial con el país asiático para el periodo señalado.

Aunque dicho trabajo fue realizado utilizando los datos de exportaciones en el mercado global, los autores señalaron que los resultados sugerían que "China podría poner en riesgo algunas exportaciones mexicanas en los mercados externos" y añadieron que dichas conclusiones concordaban con el comportamiento que se estaba observando específicamente en el mercado estadounidense.

Los resultados calculados en este estudio para el periodo 1996-2009 pueden consultarse en el anexo 1. Se refieren específicamente al CS, al CC y al Cl entre México y China, en cuanto al total de sus exportaciones dirigidas hacia Estados Unidos. Asimismo, se obtuvo el promedio del índice $\mathrm{Cl}$ para cada uno de los periodos mencionados en el apartado 1, a fin de detectar a través de esta metodología si la competencia entre China y México en el mercado mencionado se ha reducido o no. Los resultados se presentan en la tabla 2.

\section{Tabla 2: Cl promedio entre México y China por periodo, para el total de sus} exportaciones hacia Estados Unidos

\begin{tabular}{|c|c|}
\hline Periodo & CI \\
\hline $1996-2000$ & 0,3547 \\
\hline $2001-2003$ & 0,3998 \\
\hline $2004-2008$ & 0,3960 \\
\hline 2009 & 0,4705 \\
\hline
\end{tabular}

Fuente: Elaboración propia a partir de cálculos de coeficientes en base a datos de la United States International Trade Commission.

Nota: Se tomó como referencia el periodo 19962000 en lugar de 1994-2000 (que era el que se mencionaba en el apartado 1), debido a que los datos de la United States International Trade Commission de 1994 y 1995 desagregados al nivel SITC-3, no eran comparables a los de 1996 en adelante.

Dichos resultados muestran que, durante el periodo 2001-2003, la competencia entre China y México en el mercado estadounidense fue mayor que en el periodo previo, lo cual es acorde al retroceso que las exportaciones mexicanas hacia dicho destino sufrieron en términos de valor, TMCA y participación de mercado. Para el periodo de mayor interés de este estudio: 2004-2008, se observan resultados prácticamente iguales (aunque ligeramente inferiores) a los de 2001-2003 en la similitud de la estructura exportadora de ambos países a Estados Unidos y por ende, en los potenciales niveles de competencia entre México y China en dicho mercado. Por el contrario, para 2009 se observa un notable aumento en este indicador. (Ver tabla 2).

Como se mencionó al final del apartado 1, la recuperación observada en las exportaciones mexicanas hacia Estados Unidos en el periodo 2004-2008 podía

\footnotetext{
${ }^{13}$ Blázquez-Lidoy, Rodríguez y Santiso (2006).
} 
Cabranes, Flora. Exportaciones chinas y mexicanas hacia Estados Unidos: ¿sigue China afectando a México?

deberse a que la competencia entre China y México se hubiera reducido; sin embargo, la reducción en el índice $\mathrm{Cl}$ para dicho periodo fue tan leve, que no permite afirmar que ésta sea la causa.

Tomando en cuenta que una parte importante de las exportaciones mexicanas a Estados Unidos corresponden al sector energético (alrededor del 15\% en $2009^{14}$ ), cuyo comportamiento depende en gran medida de las fluctuaciones en los precios internacionales de petróleo y que además, tiene un peso insignificante para las exportaciones chinas, se calcularon también los mismos índices, pero eliminando a dicho sector. Los resultados obtenidos para cada índice y año se pueden consultar en el anexo 2, mientras que los promedios del índice $\mathrm{Cl}$ para cada periodo, se presentan en la tabla 3.

Tabla 3: Cl promedio entre México y China por periodo, para sus exportaciones hacia Estados Unidos, excluyendo al sector energético

\begin{tabular}{|c|c|}
\hline Periodo & Cl \\
\hline $1996-2000$ & 0,3726 \\
\hline $2001-2003$ & 0,4332 \\
\hline $2004-2008$ & 0,4863 \\
\hline 2009 & 0,5057 \\
\hline
\end{tabular}

Fuente: Elaboración propia a partir de cálculos de coeficientes en base a datos de la United States International Trade Commission.

Los datos muestran claramente que la estructura exportadora de ambos países hacia Estados Unidos, excluyendo al sector energético, ha tendido a parecerse más a lo largo del tiempo y por tanto, su potencial competencia comercial en dicho mercado ha aumentado. Esto lleva a concluir que, o bien las exportaciones no energéticas mexicanas a Estados Unidos se recuperaron, a pesar de que su competencia con China hubiera aumentado; o la mejoría observada en el apartado 1 se debió básicamente al sector energético. Sobre este punto se volverá en el apartado 3.

No obstante la claridad de los resultados observados, es importante señalar algunas limitaciones de los indicadores utilizados, en el sentido de que, como señala Romero (2009), aunque el CC es uno de los más empleados en este tipo de análisis y mide adecuadamente el grado de similitud de la estructura exportadora de dos países, una de sus críticas es que no refleja realmente el grado de competencia en un tercer mercado cuando el tamaño de sus exportaciones es muy distinto. Esto podría aplicar también para el CS, pues al igual que el CC se basa en participaciones de mercado y no en valores absolutos exportados. Por este motivo, se decidió añadir el uso de otro indicador, el cual se presenta a continuación.

\section{2 Índice de especialización de Balassa}

Como señalan Correa y Gómez (2010), los indicadores de Ventaja Comparativa Revelada (VCR) corresponden a una propuesta de la teoría económica convencional

\footnotetext{
${ }^{14}$ Según cálculos realizados a partir de datos de la United States International Trade Commission (2010).
} 
Cabranes, Flora. Exportaciones chinas y mexicanas hacia Estados Unidos: ¿sigue China afectando a México?

como parte del análisis de los patrones de especialización en el comercio internacional. El diseño original de VCR fue la propuesta de Bela Balassa (1965), como parte del análisis de los patrones de especialización del comercio, aunque ha tenido diversas variantes. Una de ellas es la que se utiliza en este estudio, aplicada también por Blázquez-Lidoy, Rodríguez y Santiso (2006) y Romero (2009), los cuales probaban el efecto negativo de China en las exportaciones mexicanas.

Este índice contrasta el peso de un sector o producto en el total de las exportaciones de un país, ya sea hacia el mundo o hacia un tercer país, con la participación de dicho sector o producto en las importaciones totales del mercado seleccionado. Al igual que los demás indicadores de VCR, es estático y se calcula para cada periodo (aunque se pueden realizar mediciones de estática comparada, contrastando su tasa de cambio de un periodo a otro) y una de sus limitaciones es que no considera las importaciones contenidas en las exportaciones, que para México y China pueden ser importantes debido a sus elevados niveles de actividades de ensamblado o maquila. (Correa, 2008).

Otra de sus limitaciones, señalada por Correa (2008) y que también aplica para los índices de similitud utilizados anteriormente, es que muestra el desempeño y la especialización de ambos países, incluso ofreciendo una idea general de las tendencias sectoriales, pero escapan al análisis los factores determinantes o causas del desempeño observado.

Para el presente trabajo, se calculó este índice para cada uno de los 10 sectores en que el SITC clasifica a los productos de exportación ${ }^{15}$, tanto para China como para México, con respecto al mercado de Estados Unidos, para cada uno de los años comprendidos entre 1996 y 2009.

Cabe señalar que aunque este tipo de análisis se puede realizar a nivel sector o a nivel producto, hacerlo sectorialmente es sólo ilustrativo y sus resultados deben ser interpretados únicamente como imagen de algunas tendencias, mientras que un elevado nivel de desagregación garantiza que los productos comparados sean realmente comparables (Jenkins, 2009; Romero, 2009; y Correa y Gómez, 2010), ya que es posible que de acuerdo a este indicador dos países se especialicen en el mismo sector pero realmente no estén compitiendo entre sí directamente, por especializarse en productos distintos del mismo sector. El alcance de este trabajo impide una desagregación mayor, aunque sería interesante aplicarla en análisis posteriores.

La fórmula utilizada fue la siguiente:

$$
I E B_{s t}^{j}=\left(\frac{X_{s t}^{j} / \sum_{s} X_{s t}^{j}}{M_{s t}^{E U A} / \sum_{s} M_{s t}^{E U A}}\right)
$$

\footnotetext{
${ }^{15}$ Los datos para calcular este índice fueron también tomados de la United States International Trade Commission (2010), tomando como referencia el valor CIF de las importaciones de Estados Unidos, tanto globales como provenientes de México y de China. Se tomó la clasificación SITC a un dígito.
} 
Cabranes, Flora. Exportaciones chinas y mexicanas hacia Estados Unidos: ¿sigue China afectando a México?

donde:

- $I E B_{s z}^{j}$ es el índice de especialización de Balassa del país j para el sector s y el periodo t.

- $X_{s t}^{l}$ son las exportaciones del país j del sector s hacia Estados Unidos en el periodo $t$.

- $M_{s t}^{E V A}$ son las importaciones totales de Estados Unidos del sector s en el periodo t.

Un índice superior a 1 para un sector indica que el país en cuestión tiene ventaja comparativa revelada; es decir, está especializado en el mismo. Si dos países coinciden en su especialización en algún sector, esto indica la existencia de una probable competencia en él.

Los resultados completos se presentan en los anexos 3 y 4 y muestran que en el mercado estadounidense, China tiene ventaja comparativa en: Manufacturas diversas; maquinaria y equipo de transporte; y bienes manufacturados clasificados principalmente por material; por su parte, México tiene ventaja en: Maquinaria y equipo de transporte; productos alimenticios y animales vivos; bebidas y tabaco; y mercancías no clasificadas en otra parte.

La coincidencia de ambos en maquinaria y equipo de transporte, refleja una probable competencia en este sector. Cabe destacar que China no tenía ventaja comparativa en éste y que comenzó a tenerla en 2004, año en que experimentó un notable incremento de esta partida, llegando a representar este sector el $46,6 \%$ de sus exportaciones para dicho periodo. Esto indica que, al parecer, en los últimos años la competencia comercial entre México y China lejos de disminuir, ha aumentado. Además, la ventaja comparativa en ambos ha crecido ininterrumpidamente desde 2004 hasta 2008, lo cual refleja una tendencia creciente en la probable competencia en este rubro. Como puede observarse en el gráfico 5, desde 2004 éste es el principal sector de exportación para ambos países y en el caso de México, tuvo un retroceso en 2001-2003, con una recuperación en 20042007, a pesar del aumento de la competencia china.

Cabe resaltar que estos resultados apuntan a un aumento en la competencia entre ambos países para este sector en su conjunto; sin embargo, cabría la posibilidad de que los dos tuvieran ventaja comparativa a la vez en este rubro, pero que estuvieran especializándose en productos diferentes. El alcance de este trabajo impide realizar un análisis más pormenorizado, aunque sería interesante incluir este aspecto en alguna investigación posterior.

Del análisis completo de este apartado se desprende que las estructuras exportadoras de China y México con respecto al mercado estadounidense al parecer han seguido compitiendo en el periodo 2004-2009, tanto o incluso más que antes, siendo un caso especial el del sector de maquinaria y equipo de transporte, que es el de mayor peso para ambos países y el de mayor probable competencia entre sí. No obstante, se observa que en 2004-2007 este sector tuvo un importante crecimiento en México (ver gráfico 5). Esto lleva a concluir que la recuperación presentada en el apartado 1 aparentemente no se debe a una reducción en la competencia entre China y México, lo que lleva a preguntarse cuál es entonces la 
Cabranes, Flora. Exportaciones chinas y mexicanas hacia Estados Unidos: ¿sigue China afectando a México?

causa y si ésta puede deberse a que México esté compitiendo mejor o a razones coyunturales, lo que conduce al siguiente apartado.

\section{Gráfico 5: Evolución en el valor de los principales sectores de exportación de México y China hacia Estados Unidos (1996-2009)}
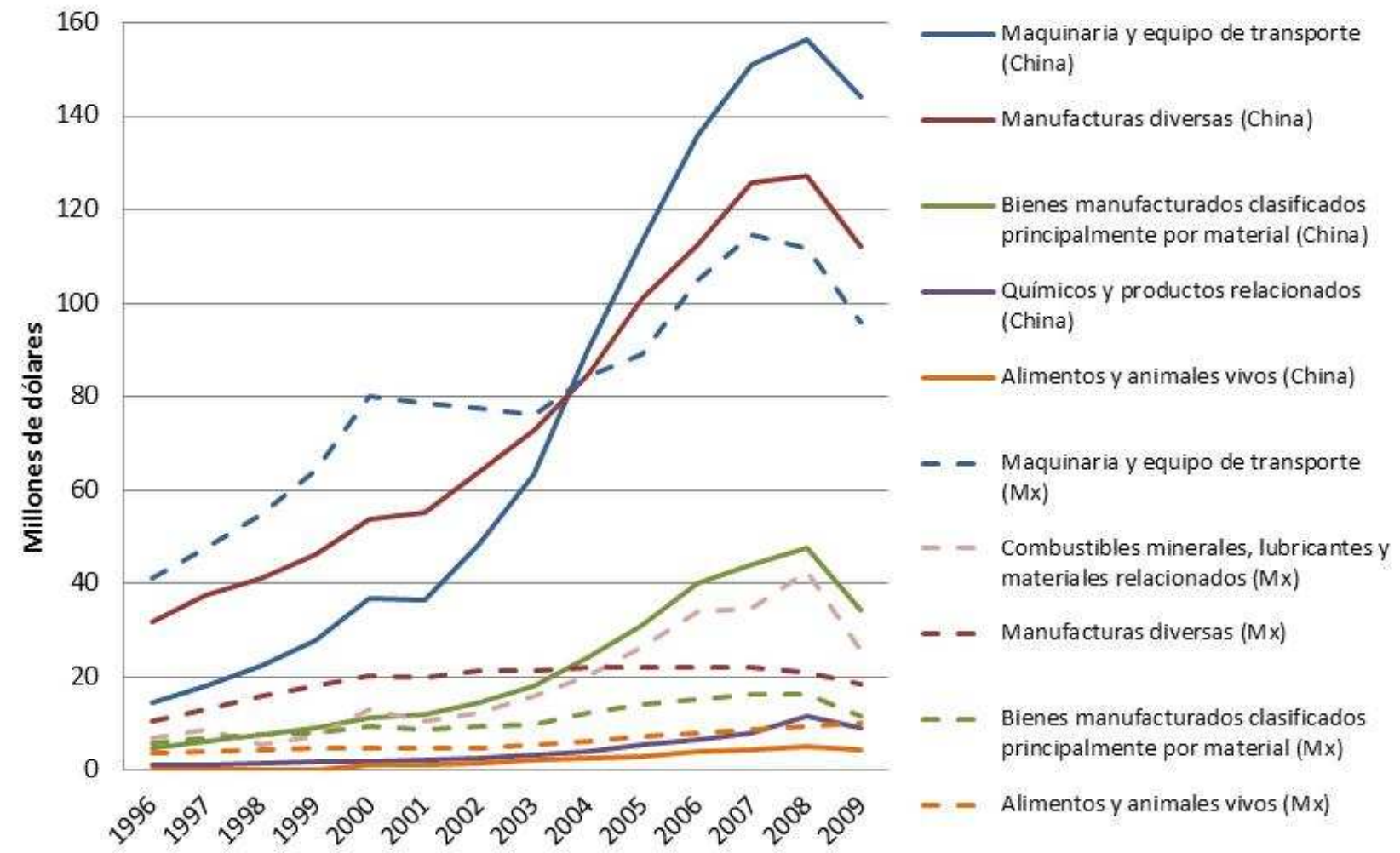

Fuente: Elaboración propia con datos de la United States International Trade Comission. Nota: Se eligieron los cinco principales sectores de exportación para cada país.

\section{POSIBLES CAUSAS DE LA RECUPERACIÓN DE LAS EXPORTACIONES MEXICANAS A ESTADOS UNIDOS EN EL PERIODO 2004-2008}

Hasta ahora se ha apuntado a que la recuperación de México puede haberse debido a que este país haya logrado competir mejor con China en cuanto a sus exportaciones a Estados Unidos; y/o a causas coyunturales. Entre las primeras pudieran encontrarse factores tales como una mayor competitividad en ciertos rubros específicos en los que ambos países compiten (específicamente en el sector de maquinaria y equipo de transporte), un aumento en la inversión extranjera directa (IED) y/o en el número de empresas maquiladoras ${ }^{16}$, un mejor aprovechamiento de las ventajas geográficas, alteraciones en el coste de la mano de obra; o cambios efectivos en materia de políticas públicas mexicanas. Entre las segundas, pudieran darse aspectos tales como aumentos en el precio de los energéticos que favorecieran el incremento en el valor de las exportaciones petroleras mexicanas; o variaciones en el tipo de cambio, entre otros.

\footnotetext{
${ }^{16}$ Ya que como se indicó, una parte importante de las exportaciones mexicanas es realizada por empresas con capital de origen extranjero.
} 
Cabranes, Flora. Exportaciones chinas y mexicanas hacia Estados Unidos: ¿sigue China afectando a México?

El alcance de este trabajo impide ahondar demasiado en este tema. Sin embargo, tomando en cuenta que la recuperación se observó más bien en el sector petrolero y en el de maquinaria y equipo de transporte, que han sido los de mayor peso para México en los últimos años dentro del total de sus exportaciones a Estados Unidos, se exploran algunas posibles causas relacionadas con cambios específicos en estos rubros. También se trata someramente el aspecto del posible mayor aprovechamiento de las ventajas geográficas.

\section{- Sector energético y mayor aprovechamiento de las ventajas geográficas}

Si se separan las exportaciones mexicanas hacia Estados Unidos de este sector, se observa que las no energéticas tuvieron un comportamiento positivo en 2004-2007, con un leve retroceso en 2008, que se acentuó más en 2009, coincidiendo con la crisis económica iniciada en Estados Unidos (ver gráfico 6). No obstante, en 2008 el valor total de las exportaciones mexicanas a dicho mercado creció con respecto a 2007, lo cual es reflejo del incremento en los precios del petróleo, que pasaron de 64,06 dólares por barril en julio de 2007, a 122,14 dólares por barril en julio de $2008^{17}$.

\section{Gráfico 6: Valor de las importaciones estadounidenses procedentes de México (totales y sin el sector energético)}

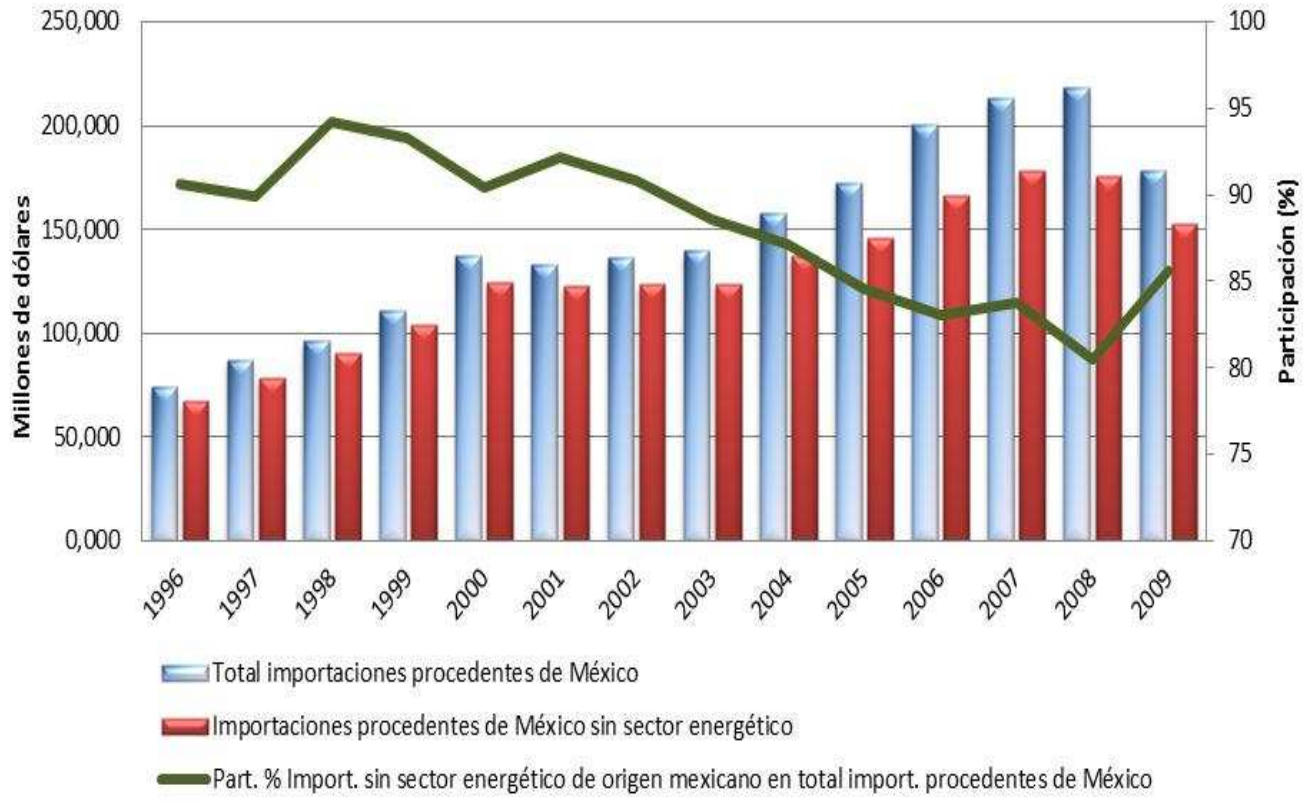

Fuente: Elaboración propia con datos de la United States International Trade Commission.

Así, lo anterior muestra que la recuperación de las exportaciones mexicanas hacia Estados Unidos observada en el periodo 2004-2008 se debió en parte al buen comportamiento del sector energético, incidiendo en gran medida en esto el incremento de los precios de petróleo, situación de carácter coyuntural. Sin embargo, como se observa en el gráfico 6, para 2004-2007 el resto de las exportaciones mexicanas hacia dicho mercado también experimentaron una

\footnotetext{
${ }^{17}$ Datos tomados del IMP (2010). Se refieren al precio de la mezcla del petróleo mexicano. Julio fue el mes de 2008 en que el precio alcanzó un valor más elevado, aunque en diciembre del mismo año, el precio se desplomó hasta alcanzar 32,41 dólares por barril.
} 
Cabranes, Flora. Exportaciones chinas y mexicanas hacia Estados Unidos: ¿sigue China afectando a México?

recuperación al menos en términos de valor, aun cuando su participación dentro del total exportado por México hacia Estados Unidos se redujo.

Por otro lado, cabe destacar que además de los impactos directos del aumento del precio del petróleo en las exportaciones mexicanas al incrementarse el valor de las ventas del sector energético a Estados Unidos éste ha generado, según apuntan Guerrero y Padilla (2010), un impacto directo en los costos de transporte de los bienes comerciados internacionalmente.

De acuerdo a los autores, México (junto con otros países de América Central y el Caribe), tiene un modelo de exportación basado en las ventajas comparativas estáticas, en el que resulta decisiva la cercanía geográfica con Estados Unidos, además del bajo coste de la mano de obra y las preferencias arancelarias. Asimismo, argumentan que un mayor precio del petróleo aumenta la competitividad de las exportaciones mexicanas, en contraposición a las de países lejanos, sobre todo algunos asiáticos, como sería el caso de China.

El mecanismo de transmisión sería el siguiente: un mayor precio del petróleo aumentaría los costes de transporte, lo cual ocasionaría un aumento en los precios relativos de los bienes procedentes de los países lejanos al mercado de destino (tal sería el caso de China), lo que incrementaría la competitividad de los países cercanos (como México) y con ello, su participación de mercado.

Según dicho estudio, el coste de transportar cualquier producto desde México hacia Estados Unidos es por lo menos la mitad de lo que costaría hacerlo desde China. Por tanto, todo esto podría haber tenido también cierto peso en la recuperación de las exportaciones mexicanas observada para los últimos años en este análisis, favoreciento especialmente a ciertos productos de valor bajo o medio, en los que el costo de transporte representa una parte importante de su precio final de exportación; o a los de gran volumen o peso.

Sin embargo, cabe matizar que, como indican Guerrero y Padilla (2010), esto podría no traducirse en una ventaja si los países asiáticos llevan a cabo estrategias más efectivas que los que gozan de proximidad geográfica, para amortiguar el traspaso del incremento del costo de transporte al precio absoluto.

El estudio citado considera que la tendencia al alza en el precio del petróleo se mantendrá en el mediano y largo plazo, cuestión que seguiría impactando positivamente a los países cercanos a Estados Unidos, como México, si como hasta el momento no se conocen energías alternativas para el transporte de carga marítima. Sus autores incluso mencionan que, de acuerdo a ciertas posiciones extremas, de mantenerse los precios elevados del petróleo se esperaría un mayor consumo de bienes locales y un reajuste de las estrategias de localización de la producción hacia países con costos de transporte inferiores.

Como señalan Guerrero y Padilla (2010), México puede beneficiarse de los incrementos en el precio del petróleo para aprovechar aun más la ventaja de su proximidad geográfica con respecto a Estados Unidos, pero dicho factor puede ser muy volátil y depender de él dejaría al país en una situación vulnerable, por lo que 
Cabranes, Flora. Exportaciones chinas y mexicanas hacia Estados Unidos: ¿sigue China afectando a México?

sería recomendable que las autoridades mexicanas tomaran medidas para mejorar su eficiencia logística y su infraestructura, específicamente la portuaria.

Lo anterior sería relevante porque permitiría reducir los costes asociados al transporte y por tanto, los precios finales de sus productos de exportación, aumentando su competitividad exportadora. Además, como señalan BlázquezLidoy, Rodríguez y Santiso (2006), la distancia introduce demoras en los procesos, mientras que la cercanía tiene efectos cualitativos en la sincronización de las tareas y la entrega de los productos, permitiendo que los comerciantes minoristas reaccionen con rapidez y eficacia a las fluctuaciones de la demanda final, sin tener que mantener costosas existencias y es importante en la transición hacia modelos de producción flexible que permitan cubrir con rapidez cambios no esperados en la demanda (Guerrero y Padilla, 2010). Asimismo, según algunas estimaciones citadas por los primeros autores, los costes de comercio casi duplican los de producción, por lo que lograr reducirlos sería de gran importancia para México.

En cuanto a la eficiencia logística, un aspecto importante a considerar para el país latinoamericano sería la simplificación de sus procesos aduaneros ya que, como señalan Guerrero y Padilla (2010), en algunos de los principales puertos mexicanos las tarifas portuarias duplican las de algunos de Europa. Asimismo, Blázquez-Lidoy, Rodríguez y Santiso (2006) indican que, si la eficiencia de los puertos mexicanos aumentara a niveles como los de Francia y Suecia, se podría reducir alrededor del $10 \%$ de sus costes de transporte.

\section{- Sector de maquinaria y equipo de transporte}

Debido a que tradicionalmente las exportaciones de este sector provienen de empresas con capital extranjero instaladas en México, especialmente maquiladoras, se analizó el comportamiento de la IED dirigida a este sector, para el periodo 1999$2009^{18}$. Como puede verse en las tablas 4 y 5 , la IED del sector de productos metálicos, maquinaria y equipo experimentó una recuperación en 2004-2007, si se compara con el periodo 2001-2003, comportamiento muy favorable si se contrasta además con el de la IED total recibida por el país en el mismo periodo. (Cabe señalar que el $73,6 \%$ de la IED dirigida a este sector tuvo como origen a Estados Unidos). Estos resultados coinciden con el comportamiento también favorable de las exportaciones hacia Estados Unidos del sector de maquinaria y equipo de transporte que se dieron justamente en el periodo 2004-2007 (ver gráfico 5).

Tabla 4: IED recibida por México en el periodo 1999-2009, en total y dirigida al subsector de productos metálicos, maquinaria y equipo

\begin{tabular}{|c|c|c|c|c|c|c|c|c|c|c|c|}
\hline Rubro & 1999 & 2000 & 2001 & 2002 & 2003 & 2004 & 2005 & 2006 & 2007 & 2008 & 2009 \\
\hline $\begin{array}{l}\text { Productos metálicos, } \\
\text { maquinaria y equipo. }\end{array}$ & & & & & & & & & & & \\
\hline $\begin{array}{l}\text { Incluye instrumentos } \\
\text { quirúrgicos y de } \\
\text { precisión. }\end{array}$ & $5.457,20$ & $4.578,20$ & $3.463,60$ & $3.363,80$ & $3.848,20$ & $5.201,20$ & $4.078,90$ & $4.242,50$ & $4.341,50$ & $3.055,00$ & $2.889,80$ \\
\hline
\end{tabular}

Fuente: Elaboración propia con datos de la Secretaría de Economía (México)

Nota: Los datos están expresados en millones de dólares.

\footnotetext{
${ }^{18}$ En base a datos publicados por la Secretaría de Economía, de México. No hay datos publicados para años previos.
} 
Cabranes, Flora. Exportaciones chinas y mexicanas hacia Estados Unidos: ¿sigue China afectando a México?

Tabla 5: Comparación entre distintos periodos de la IED recibida por México en total y para el subsector de productos metálicos, maquinaria y equipo

\begin{tabular}{|c|c|c|c|c|c|}
\hline Rubro & $\begin{array}{l}\text { Promedio anual } \\
2001-2003 \text { (a) }\end{array}$ & $\begin{array}{l}\text { Promedio anual } \\
2004-2008 \text { (b) }\end{array}$ & $\begin{array}{c}\text { Variación b/a } \\
(\%)\end{array}$ & $\begin{array}{l}\text { Promedio anual } \\
2004-2007 \text { (c) }\end{array}$ & $\begin{array}{c}\text { Variación } \\
\text { c/a (\%) }\end{array}$ \\
\hline $\begin{array}{l}\text { Productos metálicos, } \\
\text { maquinaria y equipo. } \\
\text { Incluye instrumentos } \\
\text { quirúrgicos y de } \\
\text { precisión }\end{array}$ & $3.558,53$ & $4.183,82$ & 17,57 & $4.466,03$ & 25,50 \\
\hline Total & $23.329,70$ & $23.446,24$ & 0,50 & $23.387,20$ & 0,25 \\
\hline
\end{tabular}

Fuente: Elaboración propia con cálculos realizados a partir de datos de la Secretaría de Economía (México).

Nota: Los datos están expresados en millones de dólares.

Así, los datos apuntan a que muy probablemente parte de la recuperación observada en el sector de maquinaria y equipo de transporte se debió al incremento en la IED recibida por México en este rubro. Sería interesante realizar un análisis a profundidad de este sector, incluso a nivel producto. El alcance de este trabajo no lo permite; sin embargo, cabe señalar algunos elementos que otros autores han encontrado acerca de la evolución en la competitividad de ciertos productos específicos pertenecientes a dicho sector.

De acuerdo a Guerrero y Padilla (2010), entre 2005 y 2008 México fortaleció la competitividad de sus exportaciones en equipos y componentes electrónicos, después de un estancamiento en la misma entre 2000 y 2005 y aun a pesar de la agresiva competencia asiática. Asimismo, en 2008 este país fue el primer exportador de cables de fibra óptica, siendo China el segundo, por una gran diferencia. Para el mismo periodo, México también era competitivo y aventajaba al país oriental en interruptores automáticos de corriente y en plásticos para autos.

Asimismo, de los datos ofrecidos por Leyva (2009) se desprende que existen algunos bienes de este sector que, perteneciendo al grupo de los principales quince productos no petroleros exportados a Estados Unidos por México, mostraron desde 1996 hasta 2007 una participación en el mercado estadounidense muy superior para este país que para China.

Algunos de ellos mostraron una notable mejora en su comportamiento o una recuperación en los años más recientes del periodo señalado. Tal sería por ejemplo el caso de las partes y accesorios de automóviles y camiones, los automóviles para el transporte de mercancías, los instrumentos y aparatos de medicina, cirugía, odontología o veterinaria, los refrigeradores y demás aparatos generadores de frío y las partes de motores. Al ser casos de éxito, valdría la pena ahondar posteriormente en otros estudios a fin de conocer las causas de su competitividad, incluyendo en el análisis el comportamiento de la IED en dichos rubros específicos.

Finalmente, Correa y Gómez (2010) encontraron que para el año 2007 México tuvo una mayor presencia en opto-electrónicos y materiales avanzados. El primero es un mercado dinámico para Estados Unidos y una categoría de alta competencia donde este país mantiene una ligera delantera. Asimismo, hallaron que presentó ligeras ventajas en manufactura flexible, que es un sector con crecimiento sobre el promedio entre el total de importaciones estadounidenses; y que tuvo además 
Cabranes, Flora. Exportaciones chinas y mexicanas hacia Estados Unidos: ¿sigue China afectando a México?

ventajas en ciencias de la vida y materiales avanzados. Los autores también hallaron cierta estabilidad y mejoría en el desempeño comercial de México entre 2002 y 2007, aunque en general su análisis ratifica que China sigue desplazando los productos mexicanos. No obstante, encontraron cierta leve recuperación de México para el rubro de tecnología avanzada y para algunas ramas de ésta.

\section{CONCLUSIONES Y RECOMENDACIONES}

De acuerdo a lo observado y dando respuesta a las preguntas planteadas originalmente, se percibe que las exportaciones chinas hacia Estados Unidos han tenido un importante e ininterrumpido crecimiento de 2002 a 2008, superando a las mexicanas. Las de México, no obstante ser menores, mostraron una recuperación en el periodo 2004-2008 en comparación a 2001-2003, aunque sin que se lograran alcanzar los niveles previos a 2001, que fueron los de mayor auge para México. Esta recuperación se dio tanto en valor y TMCA, como en participación del mercado estadounidense, lo cual tiene más peso si se toma en cuenta que la concentración de las exportaciones mexicanas hacia Estados Unidos se redujo ${ }^{19}$.

El análisis del apartado 2 muestra que los productos chinos y los mexicanos no sólo siguieron compitiendo en el mercado estadounidense en el periodo 2004-2008 sino que, si se excluye al sector energético, esta competencia aumentó, ya que las estructuras exportadoras de ambos países hacia dicho mercado se volvieron incluso más parecidas que en 1996-2000 y que en 2001-2003.

Por sectores, se observa que tanto China como México han tenido una ventaja comparativa creciente en 2004-2008 con respecto al mercado estadounidense en el sector de maquinaria y equipo de transporte, que es el de mayor importancia para ambos. China comenzó a tener ventaja comparativa en este sector desde 2004, cuando México ya llevaba varios años teniéndola.

Los resultados encontrados apuntan a que al parecer la competencia entre ambos países en dicho mercado para este rubro ha aumentado en 2004-2008 es decir, justamente en el periodo de recuperación de las exportaciones mexicanas a Estados Unidos. Sin embargo, cabe matizar que los hallazgos obtenidos a nivel sectorial deben interpretarse con ciertas reservas, ya que para tener resultados más certeros acerca de la competencia comercial entre ambos países sería necesario hacer un análisis con un mayor nivel de desagregación. No obstante, trabajos como el de Guerrero y Padilla (2010) confirman que al menos algunos productos pertenecientes al sector mencionado y en los que México ha aumentado sus ventajas comparativas en los últimos años, sí presentan una fuerte competencia con los de origen chino.

Si aparentemente la competencia entre México y China se ha incrementado en 2004-2008, ¿a qué puede deberse entonces la recuperación de las exportaciones mexicanas al mercado de referencia en dicho periodo? Se necesitaría ahondar en dicha cuestión y explorar con profundidad las posibles causas estructurales y coyunturales, lo cual rebasa el alcance de este trabajo. A pesar de ello, del presente análisis pueden extraerse algunas conclusiones. Una parte pudo deberse a la salida

\footnotetext{
${ }^{19}$ Dichos indicadores mostraron en general una recuperación en el periodo señalado, aunque no en cada año.
} 
Cabranes, Flora. Exportaciones chinas y mexicanas hacia Estados Unidos: ¿sigue China afectando a México?

de Estados Unidos de la crisis de 2001, lo cual habría dinamizado su demanda, aunque el incremento en la participación en los productos mexicanos no se explicaría por esto.

El análisis realizado en el apartado 3 apunta a que parte de la recuperación fue debida al buen comportamiento del sector energético mexicano en 2004-2008, periodo en el cual los precios del petróleo se incrementaron, al igual que la participación de este sector en las importaciones estadounidenses procedentes del país latinoamericano.

Asimismo, los resultados obtenidos por el citado estudio de Guerrero y Padilla (2010) apuntan a que este aumento en los precios del petróleo también pudo haber repercutido positivamente en la recuperación de las exportaciones mexicanas de forma indirecta, encareciendo los costos de transporte de países lejanos como China y por ende, brindando una mayor competitividad a los productos de origen mexicano, que pudieron aprovechar con más fuerza la ventaja de su proximidad geográfica al mercado estadounidense.

Al parecer, otra parte de la recuperación se debió a un aumento en la IED recibida por México en el sector de productos metálicos, maquinaria y equipo en 2004-2007, coincidiendo con la recuperación de las exportaciones no energéticas en el mismo periodo, las cuales tuvieron como principal motor al sector de maquinaria y equipo de transporte. El incremento en la IED recibida habría sido relevante debido a que en México, las exportaciones de este rubro son realizadas principalmente por empresas de origen extranjero instaladas en su territorio.

Aunque se necesitaría ahondar más en otras posibles razones que expliquen la recuperación de las exportaciones mexicanas hacia Estados Unidos, las tres posibles causas señaladas apuntan hacia algo más bien de carácter externo, lo que deja a México en una posición muy vulnerable con respecto a los vaivenes de la economía internacional y en especial, de la estadounidense, principal fuente de la IED mexicana. Guerrero y Padilla (2010) señalan que se espera que el precio del petróleo continúe ubicándose en niveles altos, lo cual favorecería doblemente a las exportaciones mexicanas; sin embargo, sería riesgoso para México basar su competitividad exportadora en esto.

Por otro lado, cabe señalar que 2009 ha sido un año de comportamiento atípico, debido a la crisis económica internacional iniciada en Estados Unidos, siendo uno de sus efectos la contracción de la demanda de este país, lo que se reflejó en un descenso de las importaciones estadounidenses totales y de las provenientes de México y China. Si el primero desea recuperarse de nuevo y no perder la batalla ante este país asiático, sería conveniente que tomara medidas ya sea para lograr ventajas competitivas en los sectores de mayor competencia y/o para obtener 0 incrementar sus ventajas comparativas en productos en los que China no se especializa.

Independientemente del camino que eligiera en este sentido, sería recomendable que México emprendiera acciones tendientes a fortalecer sus exportaciones hacia Estados Unidos en productos que a la vez tuvieran un mercado dinámico, pues no es igual de ventajoso ganar participación en un mercado en expansión a ganarla en 
Cabranes, Flora. Exportaciones chinas y mexicanas hacia Estados Unidos: ¿sigue China afectando a México?

uno en contracción. De hecho, en este rubro el país latinoamericano todavía tiene mucho por hacer ya que, según Guerrero y Padilla (2010), para 2008 sólo 39\% de los productos de exportación mexicanos se orientaron hacia sectores dinámicos en las importaciones de Estados Unidos. Además, 33,1\% de éstos correspondieron a productos en los que el mercado estadounidense se ha mostrado dinámico con respecto a 2002, pero en los que México no ha ganado competitividad.

Por el contrario, China ha estado aprovechando prácticamente la totalidad de los mercados dinámicos, ganando competitividad en ellos. Sólo un $0,01 \%$ de los productos chinos se orienta hacia sectores dinámicos en los que no ha ganado competitividad, en contraste con el $33,1 \%$ citado para el caso mexicano.

Por otro lado, sería también conveniente que México desarrollara algunas estrategias orientadas a la mejora de su eficiencia logística y de la calidad de su infraestructura, especialmente en el área portuaria, a fin de aprovechar mejor su ventaja geográfica y no depender mucho en este sentido de las fluctuaciones del precio del petróleo que pudieran elevar su competitividad. La importancia de la infraestructura queda de manifiesto en el Índice de Competitividad del Foro Económico Mundial, el cual la considera como uno de los doce pilares de la competitividad.

En dicho aspecto, México todavía tiene un área de oportunidad muy grande, ya que según dicha fuente, en 2009 este país se ubicaba en el puesto número 69 en infraestructura (con respecto a un total de 133 países) y en 2010, descendió al 75 . Sin embargo, en la portuaria se ubicó en una posición aun más desfavorecedora: en el lugar 89, habiendo perdido siete puestos con respecto a 2009. Por su parte, China se colocó en este aspecto en el puesto 61 en 2009 y en el 67 en 2010. Sería también conveniente que México mejorara su infraestructura carretera para reducir costos y agilizar el comercio. En este rubro, este país también tiene un largo camino por recorrer, ya que de 2009 a 2010 pasó del puesto 57 al 62 a nivel mundial.

Por otro lado, cabe señalar que aunque están más bien orientados hacia la facilidad para realizar negocios, algunos elementos presentes en el Reporte Anual de Competitividad Global realizado por el Foro Económico Mundial pueden resultar claves y orientar hacia aspectos en los que México debería prestar más atención si busca elevar su competitividad exportadora. En los reportes de 2009 y 2010 se detectó que los principales problemas para hacer negocios en México son la ineficiencia burocrática, corrupción, escaso acceso a la financiación, crimen y robo, todo lo cual puede estar afectando al conjunto de empresas mexicanas y por ende, también a las exportadoras.

Finalmente, desde el punto de vista analítico, valdría la pena seguir realizando estudios posteriores sobre este tema, por ejemplo analizando de forma más desglosada lo que ha ocurrido en los últimos años a nivel producto, especialmente en el caso del sector de maquinaria y equipo, para poder observar mejor las pautas de la recuperación que se encontró en este estudio, además de dar un seguimiento a su comportamiento tras el inicio de la recuperación de la crisis internacional que se detonó en 2008, pues las pautas pudieran haberse modificado. 
Cabranes, Flora. Exportaciones chinas y mexicanas hacia Estados Unidos: ¿sigue China afectando a México?

Sería conveniente incluir en futuros trabajos el impacto del transporte y de la IED en los rubros específicos que se encuentren e incluso, ahondar en aspectos institucionales y de políticas públicas que pudieran estar favoreciendo o interfiriendo en el desempeño comercial de México en el mercado estadounidense en contraste con el de China. Asimismo, sería interesante analizar a profundidad los casos de éxito que se reconozcan, acerca de productos en los que el país latinoamericano tenga ventaja competitiva, especialmente si se trata de mercados dinámicos para Estados Unidos, ya que esto permitiría extraer lecciones útiles para otros sectores, lo cual podría coadyuvar a potenciar la recuperación observada. 
Cabranes, Flora. Exportaciones chinas y mexicanas hacia Estados Unidos: ¿sigue China afectando a México?

\section{BIBLIOGRAFÍA}

Balassa, B. (1965): "Trade Liberalization And Revealed Comparative Advantages", The Manchester School of Economics and Social Studies. Vol. 32.

Blázquez-Lidoy, J., Rodríguez, J. y Santiso, J. (2006): “¿Ángel o demonio? Los efectos del comercio chino en los países de América Latina", Revista de la CEPAL. No. 90, 17-43. Disponible en:

http://www.eclac.cl/publicaciones/xml/6/27636/LCG2323eSantiso.pdf

Correa, G. (2008): "Desempeño comercial de México y China en el mercado de Estados Unidos de América", Denarius. Vol. 16, No. 2, 51-79.

Correa, G. y Gómez, J. (2010): "Competencia de México y China en el mercado de Estados Unidos de América. El caso de los bienes de tecnología avanzada", Denarius. Vol. 19, No. 1, 43-65.

Chávez, F. y Leyva, L. (2007): "México y China en el mercado estadounidense: una visión panorámica reciente, 1993-2004", Aportes, Revista de la Facultad de Economía, BUAP. No. 35, 5-28. Disponible en: http://redalyc.uaemex.mx/redalyc/pdf/376/37603502.pdf

De la Cruz, J. L., y González, P. (2007): "México y China ¿Competencia o cooperación?: algunas evidencias del mercado en Estados Unidos", IX reunión de Economía Mundial, Madrid.

Disponible en: http://www.uam.es/otros/ixrem/Comunicaciones/01-17\%20DE\%20LA\%20CRUZ\%20GALLEGOS-GONZALEZ\%20CASTRO.pdf

Durán, J. y Álvarez, M. (2008): "Indicadores de comercio exterior y política comercial: mediciones de posición y dinamismo comercial”, CEPAL, Santiago de Chile.

Guerrero, C. y Padilla, R. (2010): "Efectos del alza del precio del petróleo en la competitividad de las exportaciones manufactureras de Centroamérica, México y la República Dominicana", Sede Subregional de la CEPAL en México, México, D.F.

Guzmán, A. y Toledo, A. (2005): "Competitividad manufacturera de México y China en el mercado estadounidense". Economía UNAM. Vol. 2, No. 4, 94-137.

Instituto Mexicano del Petróleo (IMP). (s.f.): Página web del Instituto Mexicano del Petróleo. Recuperado el 30 de Junio de 2010, de "Precios del petróleo": http://www.imp.mx/petroleo/?imp=po

Instituto Nacional de Estadística, Geografía e Informática (INEGI): Banco de Información Económica. Recuperado el 21 de abril de 2011 de: http://dgcnesyp.inegi.org.mx/cgi-win/bdieintsi.exe/Consultar

Iranzo, S. y Ma, A. (2006): "The effect of China on Mexico-U.S. Trade: Undoing NAFTA?", Working Paper. University of Sidney and University of San Diego. Disponible en:

http://www.sandiego.edu/peacestudies/documents/tbi/iranzo_ma_TBI.pdf

Jenkins, R. (2009): "El impacto de China en América Latina", Revista CIDOB d'Afers Internacionals. No. 85-86, 251-272.

Krugman, P (2009): "El retorno de la economía de la Depresión y la crisis actual", Ed. Crítica, Barcelona.

Leyva, L. (2009): “¿Es la competencia comercial con China la única explicación de la pérdida de mercado de México en Estados Unidos?", Reporte Macroeconómico de México. Vol. 1, No. 1, 17-33.

Palazuelos, E. (2009): "El agotamiento del modelo de crecimiento 1981-2009", Mimeo. 
Cabranes, Flora. Exportaciones chinas y mexicanas hacia Estados Unidos: ¿sigue China afectando a México?

Romero, J. (2009): "Medición del impacto de los acuerdos de libre comercio en América Latina: el caso de México", Serie Estudios y Perspectivas, Sede Subregional de la CEPAL en México. No. 114.

Rosas, M. (2010): "Encuentros y desencuentros: las relaciones entre México y la República Popular China", Nueva Sociedad. No. 228, 116-136.

Secretaría de Economía (SE). (s.f.): Reporteador de los flujos de inversión extranjera directa en México. Recuperado el 15 de Junio de 2010, de: http://www.sirnie.economia.gob.mx/cgi-bin/repie.sh/reportes/selperiodo

Secretaría de Economía (SE). (s.f.): Estadísticas de comercio internacional. Recuperado el 8 de Junio de 2010, de: http://www.economia.gob.mx/?P=5400

Schwab, K., Sala-i-Martin, X., Greenhill, R., Blanke, J., Drzeniek, M., Mia, I., et. Al (2009): "The Global Competitiveness Report 2009-2010", World Economic Forum, Génova, Suiza. Disponible en:

http://www3.weforum.org/docs/WEF_GlobalCompetitivenessReport_2009-10.pdf

Schwab, K., Sala-i-Martin, X., Dervis, K., Haussman, R., Larraín, F. y Elka, M. (2010): "The Global Competitiveness Report 2010-2011", World Economic Forum, Génova, Suiza. Disponible en:

http://www3.weforum.org/docs/WEF_GlobalCompetitivenessReport_2010-11.pdf

United Nations Conference on Trade and Development (UNCTAD). (s.f.): UNCTAD Handbook of Statistics 2009. Recuperado el 16 de Mayo de 2010, de: http://stats.unctad.org/Handbook/ReportFolders/reportFolders.aspx?sRF_ActiveP ath $=P, 1283 \& s R F \_$Expanded $=, P, 1283$

United States International Trade Commission. (s.f.): Interactive Tariff and Trade DataWeb. Recuperado el 29 de Mayo de 2010, de: http://dataweb.usitc.gov/ 
Cabranes, Flora. Exportaciones chinas y mexicanas hacia Estados Unidos: ¿sigue China afectando a México?

\section{ANEXOS}

Anexo 1: Coeficientes de especialización (CS), de conformidad (CC) y promedio de ambos $(\mathrm{Cl})$ entre México y China (con respecto al total de sus exportaciones dirigidas hacia Estados Unidos)

\begin{tabular}{|cccc|}
\hline Año & CS & CC & Cl \\
\hline $\mathbf{1 9 9 6}$ & 0,3926 & 0,2405 & 0,3165 \\
\hline $\mathbf{1 9 9 7}$ & 0,4109 & 0,258 & 0,3344 \\
\hline $\mathbf{1 9 9 8}$ & 0,4335 & 0,2927 & 0,3631 \\
\hline $\mathbf{1 9 9 9}$ & 0,4386 & 0,3243 & 0,3814 \\
\hline $\mathbf{2 0 0 0}$ & 0,4318 & 0,3246 & 0,3782 \\
\hline $\mathbf{2 0 0 1}$ & 0,4443 & 0,3449 & 0,3946 \\
\hline $\mathbf{2 0 0 2}$ & 0,445 & 0,3717 & 0,4084 \\
\hline $\mathbf{2 0 0 3}$ & 0,4305 & 0,3626 & 0,3965 \\
\hline $\mathbf{2 0 0 4}$ & 0,4274 & 0,3773 & 0,4023 \\
\hline $\mathbf{2 0 0 5}$ & 0,4189 & 0,3532 & 0,3861 \\
\hline $\mathbf{2 0 0 6}$ & 0,415 & 0,3303 & 0,3727 \\
\hline $\mathbf{2 0 0 7}$ & 0,4362 & 0,3935 & 0,4148 \\
\hline $\mathbf{2 0 0 8}$ & 0,4342 & 0,3745 & 0,4043 \\
\hline $\mathbf{2 0 0 9}$ & 0,4558 & 0,4852 & 0,4705 \\
\hline
\end{tabular}

Fuente: Elaboración propia a partir de cálculos de coeficientes en base a datos de la United States International Trade Commission.

Anexo 2: Coeficientes de especialización (CS), de conformidad (CC) y promedio de ambos $(\mathrm{Cl})$ entre México y China (con respecto a sus exportaciones dirigidas hacia Estados Unidos, excluyendo al sector energético)

\begin{tabular}{|ccc|c|}
\hline Año & CE & CC & CI \\
\hline $\mathbf{1 9 9 6}$ & 0,4066 & 0,2536 & 0,3301 \\
\hline $\mathbf{1 9 9 7}$ & 0,4281 & 0,2826 & 0,3554 \\
\hline $\mathbf{1 9 9 8}$ & 0,4449 & 0,3033 & 0,3741 \\
\hline $\mathbf{1 9 9 9}$ & 0,4551 & 0,3452 & 0,4001 \\
\hline $\mathbf{2 0 0 0}$ & 0,4531 & 0,3534 & 0,4033 \\
\hline $\mathbf{2 0 0 1}$ & 0,4603 & 0,3696 & 0,4150 \\
\hline $\mathbf{2 0 0 2}$ & 0,4676 & 0,4124 & 0,4400 \\
\hline $\mathbf{2 0 0 3}$ & 0,4575 & 0,4318 & 0,4447 \\
\hline $\mathbf{2 0 0 4}$ & 0,4640 & 0,4728 & 0,4684 \\
\hline $\mathbf{2 0 0 5}$ & 0,4611 & 0,4792 & 0,4701 \\
\hline $\mathbf{2 0 0 6}$ & 0,4631 & 0,4631 & 0,4631 \\
\hline $\mathbf{2 0 0 7}$ & 0,4810 & 0,5303 & 0,5057 \\
\hline $\mathbf{2 0 0 8}$ & 0,4905 & 0,5577 & 0,5241 \\
\hline $\mathbf{2 0 0 9}$ & 0,5005 & 0,6146 & 0,5576 \\
\hline
\end{tabular}

Fuente: Elaboración propia, a partir de cálculos de coeficientes en base a datos de la United States International Trade Commission. 
Cabranes, Flora. Exportaciones chinas y mexicanas hacia Estados Unidos: ¿sigue China afectando a México?

Anexo 3: Índice de especialización de Balassa por sector, para China

\begin{tabular}{|c|c|c|c|c|c|c|c|c|c|c|c|c|c|c|}
\hline Sector & 1996 & 1997 & $\overline{1998}$ & 1999 & 2000 & 2001 & 2002 & 2003 & 2004 & 2005 & 2006 & 2007 & 2008 & 2009 \\
\hline $\begin{array}{l}\text { Mercancías y operaciones } \\
\text { no clasificadas en otro } \\
\text { rubro }\end{array}$ & 0,226 & 0,226 & 0,243 & 0,240 & 0,257 & 0,261 & 0,247 & 0,285 & 0,314 & 0,323 & 0,339 & 0,357 & 0,356 & 0,298 \\
\hline $\begin{array}{l}\text { Artículos manufacturados } \\
\text { diversos }\end{array}$ & 3,480 & 3,315 & 3,047 & 3,022 & 2,980 & 2,870 & 2,668 & 2,536 & 2,413 & 2,458 & 2,426 & 2,423 & 2,546 & 2,255 \\
\hline $\begin{array}{l}\text { Maquinaria y equipo de } \\
\text { transporte }\end{array}$ & 0,590 & 0,615 & 0,654 & 0,684 & 0,761 & 0,775 & 0,843 & 0,951 & 1,072 & 1,139 & 1,179 & 1,189 & 1,291 & 1,286 \\
\hline $\begin{array}{l}\text { Artículos manufacturados, } \\
\text { clasificados principalmente } \\
\text { según el material }\end{array}$ & 0,771 & 0,801 & 0,805 & 0,901 & 0,948 & 0,995 & 0,990 & 1,026 & 0,980 & 1,033 & 1,072 & 1,100 & 1,194 & 1,125 \\
\hline $\begin{array}{l}\text { Productos químicos y } \\
\text { productos conexos, n.e.p. }\end{array}$ & 0,354 & 0,350 & 0,341 & 0,339 & 0,302 & 0,296 & 0,265 & 0,253 & 0,255 & 0,284 & 0,290 & 0,293 & 0,385 & 0,304 \\
\hline $\begin{array}{l}\text { Aceites, grasas y ceras de } \\
\text { origen animal y vegetal }\end{array}$ & 0,071 & 0,072 & 0,071 & 0,051 & 0,064 & 0,052 & 0,042 & 0,046 & 0,038 & 0,044 & 0,050 & 0,055 & 0,052 & 0,064 \\
\hline $\begin{array}{l}\text { Combustibles y lubricantes } \\
\text { minerales y productos } \\
\text { conexos }\end{array}$ & 0,110 & 0,104 & 0,090 & 0,043 & 0,067 & 0,036 & 0,034 & 0,024 & 0,037 & 0,024 & 0,023 & 0,012 & 0,026 & 0,006 \\
\hline $\begin{array}{l}\text { Materiales crudos no } \\
\text { comestibles, excepto los } \\
\text { combustibles }\end{array}$ & 0,281 & 0,349 & 0,326 & 0,295 & 0,337 & 0,330 & 0,297 & 0,318 & 0,301 & 0,327 & 0,325 & 0,324 & 0,340 & 0,309 \\
\hline Bebidas y tabacos & 0,041 & 0,035 & 0,040 & 0,029 & 0,045 & 0,047 & 0,041 & 0,025 & 0,027 & 0,016 & 0,016 & 0,019 & 0,017 & 0,015 \\
\hline $\begin{array}{l}\text { Productos alimenticios y } \\
\text { animales vivos }\end{array}$ & 0,346 & 0,311 & 0,280 & 0,304 & 0,333 & 0,337 & 0,349 & 0,379 & 0,370 & 0,367 & 0,406 & 0,417 & 0,448 & 0,351 \\
\hline
\end{tabular}

Fuente: Elaboración propia a partir de cálculos en base a datos de la United States International Trade Commission.

Nota: Las cifras marcadas en negritas reflejan la existencia de una ventaja comparativa. De éstas, se resaltan en cursivas aquéllas donde la ventaja comparativa es compartida por los dos países. 
Cabranes, Flora. Exportaciones chinas y mexicanas hacia Estados Unidos: ¿sigue China afectando a México?

Anexo 4: Índice de especialización de Balassa por sector, para México

\begin{tabular}{|c|c|c|c|c|c|c|c|c|c|c|c|c|c|c|}
\hline Sector & 1996 & 1997 & 1998 & 1999 & 2000 & 2001 & 2002 & 2003 & 2004 & 2005 & 2006 & 2007 & 2008 & 2009 \\
\hline $\begin{array}{l}\text { Mercancías y operaciones no } \\
\text { clasificadas en otro rubro }\end{array}$ & 1,114 & 1,062 & 1,004 & 0,982 & 1,033 & 1,007 & 0,988 & 1,091 & 1,173 & 1,149 & 1,204 & 1,213 & 1,249 & 1,343 \\
\hline Artículos manufacturados diversos & 0,837 & 0,872 & 0,926 & 0,932 & 0,886 & 0,862 & 0,881 & 0,871 & 0,833 & 0,805 & 0,728 & 0,684 & 0,683 & 0,643 \\
\hline Maquinaria y equipo de transporte & 1,225 & 1,218 & 1,252 & 1,252 & 1,297 & 1,373 & 1,329 & 1,333 & 1,337 & 1,347 & 1,388 & 1,442 & 1,505 & 1,485 \\
\hline $\begin{array}{l}\text { Artículos manufacturados, } \\
\text { clasificados principalmente según } \\
\text { el material }\end{array}$ & 0,672 & 0,665 & 0,640 & 0,635 & 0,606 & 0,613 & 0,637 & 0,644 & 0,664 & 0,699 & 0,624 & 0,647 & 0,662 & 0,662 \\
\hline $\begin{array}{l}\text { Productos químicos y productos } \\
\text { conexos, n.e.p. }\end{array}$ & 0,334 & 0,317 & 0,269 & 0,246 & 0,221 & 0,203 & 0,197 & 0,200 & 0,244 & 0,256 & 0,251 & 0,225 & 0,222 & 0,194 \\
\hline $\begin{array}{l}\text { Aceites, grasas y ceras de origen } \\
\text { animal y vegetal }\end{array}$ & 0,345 & 0,183 & 0,277 & 0,266 & 0,180 & 0,188 & 0,146 & 0,246 & 0,190 & 0,203 & 0,175 & 0,186 & 0,162 & 0,120 \\
\hline $\begin{array}{l}\text { Combustibles y lubricantes } \\
\text { minerales y productos conexos }\end{array}$ & 0,999 & 1,091 & 0,876 & 0,893 & 0,861 & 0,721 & 0,906 & 0,915 & 0,909 & 0,896 & 0,944 & 0,879 & 0,841 & 0,826 \\
\hline $\begin{array}{l}\text { Materiales crudos no comestibles, } \\
\text { excepto los combustibles }\end{array}$ & 0,501 & 0,459 & 0,413 & 0,361 & 0,337 & 0,330 & 0,326 & 0,347 & 0,354 & 0,408 & 0,373 & 0,389 & 0,455 & 0,406 \\
\hline Bebidas y tabacos & 0,914 & 0,976 & 1,093 & 1,140 & 1,263 & 1,267 & 1,320 & 1,352 & 1,375 & 1,484 & 1,476 & 1,376 & 1,415 & 1,350 \\
\hline $\begin{array}{l}\text { Productos alimenticios y animales } \\
\text { vivos }\end{array}$ & 1,366 & 1,227 & 1,242 & 1,173 & 1,090 & 1,050 & 0,994 & 1,107 & 1,223 & 1,321 & 1,284 & 1,289 & 1,354 & 1,388 \\
\hline
\end{tabular}

Fuente: Elaboración propia a partir de cálculos en base a datos de la United States International Trade Commission.

Nota: Las cifras marcadas en negritas reflejan la existencia de una ventaja comparativa. De éstas, se resaltan en cursivas aquéllas donde la ventaja comparativa es compartida por los dos paíse. 